\title{
Estrogen administered after cardiac arrest and cardiopulmonary resuscitation ameliorates acute kidney injury in a sex- and age-specific manner
}

\author{
Mizuko Ikeda', Thomas Swide ${ }^{1}$, Alexandra Vayl ${ }^{2}$, Tim Lahm²,3, Sharon Anderson ${ }^{4}$ and Michael P. Hutchens ${ }^{1 *}$
}

\begin{abstract}
Introduction: There is a sex difference in the risk of ischemic acute kidney injury (AKI), and estrogen mediates the protective effect of female sex. We previously demonstrated that preprocedural chronic restoration of physiologic estrogen to ovariectomized female mice ameliorated AKI after cardiac arrest and cardiopulmonary resuscitation (CA/CPR). In the present study, we hypothesized that male mice and aged female mice would benefit from estrogen administration after CA/CPR. We tested the effect of estrogen in a clinically relevant manner by administrating it after CA/CPR.
\end{abstract}

Methods: CA/CPR was performed in young (10-15 weeks), middle-aged (43-48 weeks), and aged (78-87 weeks) C57BL/6 male and female mice. Mice received intravenous 17ß-estradiol or vehicle $15 \mathrm{~min}$ after resuscitation. Serum chemistries and unbiased stereological assessment of renal injury were completed $24 \mathrm{~h}$ after CA. Regional renal cortical blood flow was measured by a laser Doppler, and renal levels of estrogen receptor alpha (ERa) and G protein-coupled estrogen receptor (GPER) were evaluated with immunoblotting.

Results: Post-arrest estrogen administration reduced injury in young males without significant changes in renal blood flow (percentage reduction compared with vehicle: serum urea nitrogen, 30 \%; serum creatinine (sCr), 41 \%; volume of necrotic tubules (VNT), $31 \% ; P<0.05)$. In contrast, estrogen did not affect any outcomes in young females. In aged mice, estrogen significantly reduced $\mathrm{sCr}(80 \%)$ and VNT (73\%) in males and VNT (51 \%) in females. Serum estrogen levels in aged female mice after CA/CPR were the same as levels in male mice. With age, renal ERa was upregulated in females.

Conclusions: Estrogen administration after resuscitation from CA ameliorates renal injury in young males and aged mice in both sexes. Because injury was small, young females were not affected. The protective effect of exogenous estrogen may be detectable with loss of endogenous estrogen in aged females and could be mediated by differences in renal ERs. Post-arrest estrogen administration is renoprotective in a sex- and age-dependent manner.

\section{Introduction}

Acute kidney injury (AKI) is a common complication of perioperative illness, and mortality is up to $70 \%$. In noncardiac surgical patients, the incidence is $1 \%$, conferring a seven- to eight-fold increment in mortality. The most common cause of hospital-acquired AKI is whole-body hypoperfusion [1-5], which is also independently associated with perioperative AKI.

\footnotetext{
* Correspondence: hutchenm@ohsu.edu

'Department of Anesthesiology and Perioperative Medicine, Oregon Health and Science University, 3181 SW Sam Jackson Park Road, Portland, OR 97239, USA

Full list of author information is available at the end of the article
}

Overall, men are more likely to experience AKI than women $[6,7]$. Clinical data suggest that low estrogen states are associated with increased risk of AKI $[8,9]$. Data from animal models indicate that sex hormones mediate AKI; androgen and testosterone enhance the susceptibility to AKI, and estrogen is a protective factor $[10,11]$. We previously demonstrated in mice that females enjoy relative protection from AKI after wholebody ischemia-reperfusion injury, removal of physiologic estrogen worsens AKI, and preprocedural restoration of physiologic estrogen to ovariectomized female mice restores the protected state $[12,13]$. 
Although estrogens have been studied widely, whether estrogen is efficacious when administered after wholebody ischemia-reperfusion and whether such protection can be observed in males as well as females with intact ovaries have not been determined. Therefore, to gain insights into the role of estrogen as a treatment option, we determined whether a single injection of estrogen, administered on recovery from cardiac arrest and cardiopulmonary resuscitation $(\mathrm{CA} / \mathrm{CPR})$, improves $\mathrm{AKI}$ in both sexes and whether the effect is dependent on renal blood flow. It is relevant to administer estrogen in acute phase after ischemic insult in the aspect of investigating estrogen as a therapeutic agent since clinically CA is frequently unheralded, and therefore therapy is applied following resuscitation.

Clinical trials of ischemia-protective strategies proven in mice may have failed in the past because of the reliance on young mice [14-16]. Both experimental and clinical studies demonstrate the strong linkage between aging and AKI [17-19]. Clinical data suggest that women enjoy protection from AKI in general but not when undergoing cardiac and vascular surgery, settings in which patients are older than the overall surgical population [20]. This bimodal risk distribution may be a phenomenon of the menopause and changing exposure to estrogen with age. However, few studies have addressed effect modifications of aging on the association between sex and AKI. Therefore, other important questions are whether the advantage of females against AKI after whole-body ischemia is lost with age and whether this is modulated by estrogen.

Together, the major aims of the present study were (1) to determine whether post-arrest administration of estrogen reduces AKI following CA/CPR in both sexes and (2) to investigate whether aged females, the clinical population with greatest AKI risk, lose the beneficial effect of female sex or benefit from post-arrest administration of estrogen or both. A further aim was to determine whether estrogen receptor (ER) populations in the kidney, unaffected by pre-arrest hormonal manipulation, might change with age.

\section{Methods}

All experimental protocols involving animals were conducted at Oregon Health \& Science University in Portland, Oregon. All animal experiments were conducted in conformity with the National Institutes of Health guidelines for the care and use of animals in research and were specifically approved by the Oregon Health \& Science University Institutional Animal Care and Use Committee.

\section{Animals and experimental groups}

Male and female C57BL/6 mice were obtained from Charles River Laboratories (Boston, MA, USA). We used young mice (10-15 weeks), middle-aged mice (43-48 weeks), and aged mice (78-87 weeks). Experimental animals were randomized to $17 \beta$-estradiol or vehicle treatment and subsequently underwent experimental procedures.

\section{In vivo whole-body ischemia-reperfusion (CA/CPR)}

We performed normothermic $\mathrm{CA} / \mathrm{CPR}$ as previously described [12, 13, 21, 22] Briefly, mice were anesthetized with $4 \%$ isoflurane in a 2:1 air-to-oxygen mixture, and anesthesia was maintained with $1 \%-2 \%$ isoflurane. After tracheal intubation with a 22-guage Teflon catheter (BD, Franklin, NJ, USA), animals were mechanically ventilated and the electrocardiogram (EKG) was monitored continuously. For drug administration, a PE-10 catheter was inserted into the right internal jugular vein. Rectal temperature was maintained $37 \pm 5{ }^{\circ} \mathrm{C}$ throughout the experiment with a digitally controlled lamp (Cole Parmer, Vernon Hills, IL, USA). CA was induced with $50 \mu \mathrm{l}$ of $0.5 \mathrm{M}$ potassium chloride and confirmed by isoelectric EKG signal and absence of visible cardiac contraction on the chest wall. At onset of CA, the endotracheal tube was disconnected. Seven and a half minutes after onset of CA, mechanical ventilation resumed. Eight minutes after onset of $\mathrm{CA}$, chest compressions were delivered by a finger at a rate of 300 per minute, and epinephrine in $0.9 \%$ sodium chloride solution, $11-16 \mu \mathrm{g}(0.7-1.0 \mathrm{ml})$, was administered intravenously. Return of spontaneous circulation (ROSC) was confirmed by reappearance of electrical activity on the EKG and visible cardiac contractions on the chest wall. Animals were extubated when their spontaneous respiratory rate reached more than 60 breaths per minute and then were moved to a recovery cage.

\section{Preparation of $17 \beta$-estradiol and correspondent vehicle}

A previous study performed in the same laboratory demonstrated that injection of $0.5 \mu \mathrm{g}$ of $17 \beta$-estradiol resulted in a peak of serum estradiol levels shortly after administration followed by a decrease to physiologic levels within $1 \mathrm{~h}$ in male C57BL/6 mice [23]. We therefore administered $0.5,5$, and $10 \mu \mathrm{g}$ of $17 \beta$ estradiol to investigate whether any renoprotection is dose-dependent. Water-soluble cyclodextrin-encapsulated $17 \beta$-estradiol (E4389; Sigma-Aldrich, St. Louis, MO, USA) was dissolved in $0.9 \%$ sodium chloride solution to be the desired dose in $100 \mu \mathrm{l}$. Each vehicle control was rendered so as to contain the same amount of hydroxypropyl cyclodextrin as its corresponding $17 \beta$-estradiol treatment.

\section{Regional renal cortical blood flow measurement}

We measured regional renal cortical blood flow (RRCBF) in the peri-arrest period. A laser Doppler flow probe (Moor Instruments, Wilmington, DE, USA) was placed perpendicular to the surface of the right kidney via a flank 
incision and optimally positioned for maximal signal. Laser Doppler flow was measured and recorded $5 \mathrm{~min}$ before $\mathrm{CA}$, immediately before $\mathrm{CA}$, every minute during $\mathrm{CA}$, and every $5 \mathrm{~min}$ after CA for $45 \mathrm{~min}$ after ROSC for each animal treated with $17 \beta$-estradiol or vehicle at $15 \mathrm{~min}$ after ROSC. Fifty minutes after ROSC, arterial blood was aspirated from the left ventricle for blood gas assessment.

\section{Transcardial perfusion and tissue sampling}

Twenty-four hours after CA/CPR, thoracotomy was performed under deep anesthesia. After blood sampling, mice were perfused with saline, and the right kidney was snap-frozen in liquid nitrogen and stored at $-80{ }^{\circ} \mathrm{C}$ until immunoblotting. Subsequently, mice were perfused with 4. \% paraformaldehyde and then the left kidney was harvested for histological assessment.

Evaluation of serum urea nitrogen, serum creatinine, and serum estradiol levels

A point-of-care enzyme-coupled analyzer (Abaxis Medical Diagnostics, Union City, CA, USA) was used to measure serum urea nitrogen $(\mathrm{sUN})$ and serum creatinine $(\mathrm{sCr})$. $17 \beta$-estradiol concentrations were measured by using radioimmunoassay as previously described [12]. The GDN 244 antibody was used for radioimmunoassay [24]. The overall inter-assay variation for $17 \beta$-estradiol extraction radioimmunoassay was less than $15 \%$, and the intra-assay variation was less than $12 \%$.

\section{Histological evaluation of tubular injury}

An observer blinded to treatment and sex assessed histological damage by using rigorous unbiased stereology. After fixation, $6-\mu \mathrm{m}$ sagittal sections from the kidney were sampled $160 \mu \mathrm{m}$ apart and then stained with Flouro-Jade B (Histo-Chem, Jefferson, AK, USA), which stains necrotic cells bright green. Histological damage was determined in accordance with the Cavalieri principal of unbiased stereology by using Visiopharm Integrator Software (Visiopharm, Hørsholm, Denmark) and delineating the total kidney area and applying superimposed grids consisting of two marks in a fixed relation (4:64) randomly onto a field of view. The estimated volume fraction of necrotic tubules was calculated as follows:

$$
\begin{aligned}
& \text { Volume necrotic tubules }(\mathrm{VNT}) \\
& =\sum_{\text {Marks (necrotic tubules) }} / \sum_{\text {Marks (kidney) }} \times 16
\end{aligned}
$$

The sampling intensity was decided according to our previous study to obtain precise estimation with coefficient of error of less than 0.1 by using the formula of Gundersen et al. [25]. The coefficients of error for the necrotic tubules and the reference area in our study were 0.08 and 0.05 , respectively.

\section{Immunoblotting}

Expression of ER $\alpha$ and $G$ protein-coupled estrogen receptor (GPER) in homogenates of the entire right kidney obtained $24 \mathrm{~h}$ after $\mathrm{CA} / \mathrm{CPR}$ were measured by using rabbit polyclonal anti-ER $\alpha$ (clone HC-20; Santa Cruz Biotechnology, Inc., Dallas, TX, USA) and anti-GPER (clone N-15; Santa Cruz Biotechnology, Inc.) antibodies. To eliminate any effect of exogenously administered estradiol, this assay was performed only in vehicle-treated mice. Mouse monoclonal anti-vinculin (clone cp74; CalBiochem/EMD Millipore, Billerica, MA, USA) was used as loading control. Secondary antibodies were antimouse horseradish peroxidase (HRP) and anti-rabbit-HRP from GE Healthcare (Little Chalfont, Buckinghamshire, UK) and Cell Signaling Technology (Danvers, MA, USA), respectively. Tissue was homogenized in ice-cold radioimmunoprecipitation assay buffer (ThermoFisher Scientific, Waltham, MA, USA) containing protease inhibitor cocktail (Sigma-Aldrich) and PhosSTOP phosphatase inhibitor cocktail (Roche, Indianapolis, IN, USA). Protein concentration was measured by using the BCA protein assay (ThermoFisher Scientific). Western blots were performed as previously described [26]. Primary antibodies were used at a dilution of 1:50 (ER $\alpha$ ), 1:500 (GPER), or 1:2000 (vinculin) in $5 \%$ bovine serum albumin (BSA) in tris-buffered saline with Tween-20 (TBST) (25 mM Tris, $1 \mathrm{M} \mathrm{NaCl}$, $1 \%$ Tween 20). Secondary antibodies were diluted 1:2000 $(\mathrm{ER} \alpha), 1: 5000$ (GPER), or 1:15,000 (vinculin) in $5 \% \mathrm{BSA}$ in TBST.

\section{Statistical analysis}

Statistical significance was inferred from a $P$ value of less than 0.05. Two-group two-treatment analyses were performed by using two-way analysis of variance with post hoc Sidak's test. Categorical outcomes were assessed by using Fisher's exact test or chi-squared test, as appropriate. Analysis of differences in estrogen expression between young and aged mice was performed via unpaired $t$ test. All results are presented as mean \pm standard deviation. Analysis was performed with Prism 6.0 software (GraphPad Software, Inc., La Jolla, CA, USA).

\section{Results}

Male mice are more vulnerable to renal injury than female mice after CA/CPR

To evaluate the severity of AKI after CA/CPR according to sex and age, male and female $\mathrm{C} 57 \mathrm{BL} / 6$ young and middle-aged mice were subjected to $8 \mathrm{~min}$ of CA. Twenty-four hours after CPR, a blood sample was collected and kidney was harvested. Figure 1 summarizes the renal injury $24 \mathrm{~h}$ after CA/CPR according to sex and 


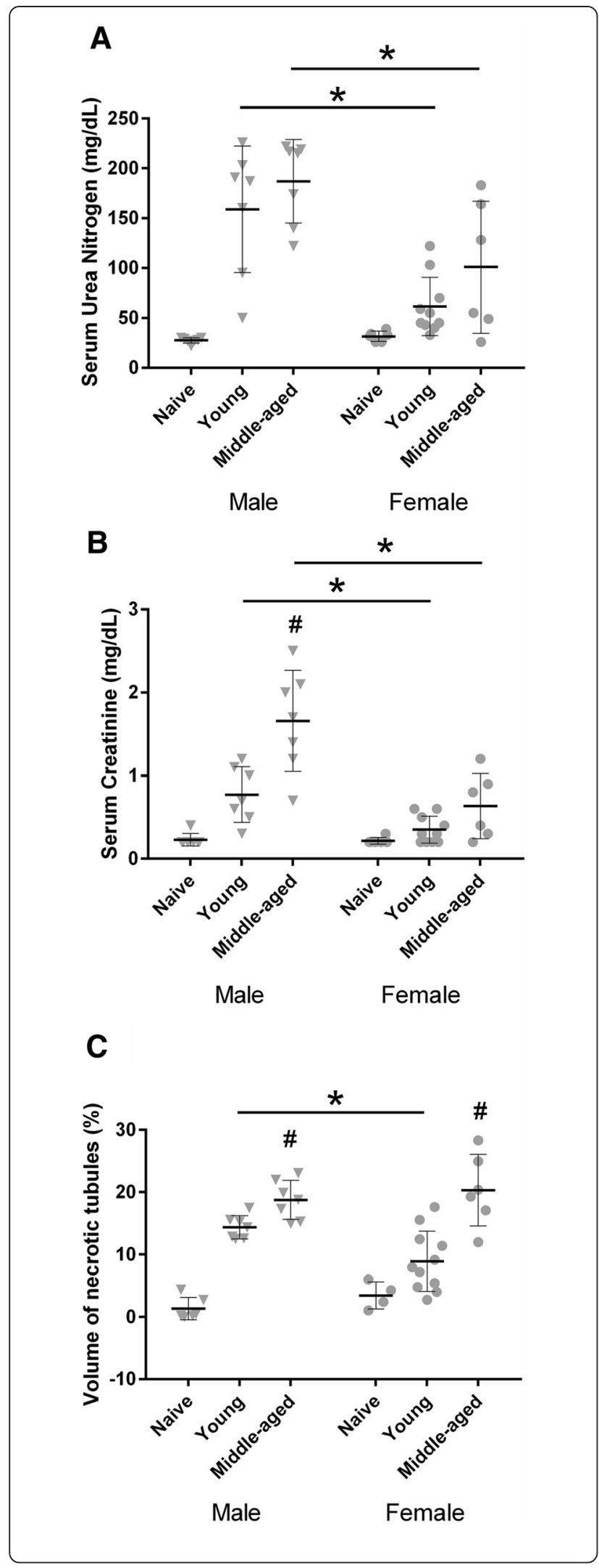

Fig. 1 Cardiac arrest and cardiopulmonary resuscitation (CA/CPR) caused renal injury in a sex- and age-specific manner. Blood and tissue samples were collected $24 \mathrm{~h}$ after CA/CPR in young (10-15 weeks) or middle-aged (43-48 weeks) male or female mice. CA/CPR caused renal injury in a sex- and age- specific manner. In young animals, female sex reduced serum urea nitrogen (a), serum creatinine (b), and necrotic tubules (c). In middle-aged animals, female sex reduced serum urea nitrogen (a) and serum creatinine (b) but not necrotic tubules (c). Data are presented as mean \pm standard deviation, $n=6-10$ per group. ${ }^{*} P<0.05$ versus same age different sex, ${ }^{\#} P<0.05$ versus same sex different age. Data were analyzed by using two-way analysis of variance with post hoc Sidak's test. Aging did not alter baseline renal function in naïve mice; therefore, we combined young and middle age naïve mice

age. CA/CPR caused renal injury in a sex-specific manner. In surgically naïve animals, $\mathrm{sUN}$ and $\mathrm{sCr}$ were equivalent between male and female (sUN: $28 \pm 2.8$ versus $30 \pm 3.5, P=0.17$; sCr: $0.23 \pm 0.08$ versus $0.22 \pm 0.04$, $P=0.73$; and volume of necrotic tubules (VNT): $1.3 \pm$ 1.8 versus $3.4 \pm 2.2, P=0.15$, male versus female). Young males developed greater renal injury than young females after CA/CPR (sUN: $159 \pm 64$ versus $62 \pm 29, P<0.01$; sCr: $0.77 \pm 0.33$ versus $0.35 \pm 0.17, P<0.01$; and VNT: $14 \pm 1.9$ versus $8.9 \pm 4.8, P<0.01$, male versus female). In middle-aged males, functional renal injury was greater than that of females after CA/CPR (sUN: $187 \pm 42$ versus $101 \pm 66, P<0.01$ and $\mathrm{sCr}: 1.7 \pm 0.6$ versus $0.63 \pm 0.4$, $P<0.01)$. Tubular necrosis, however, was equivalent between male and female middle-aged mice (VNT: $19 \pm 3.1$ versus $20 \pm 5.8, P=0.76$ ). In summary, young males suffer greater renal injury than young females after CA/CPR. Middle-aged males also demonstrate more severe post-ischemic renal dysfunction than middle-aged females; however, the severity of tubular necrosis is the same.

\section{Dose-dependent renoprotection by post-arrest administration of $17 \beta$-estradiol in young males}

To determine the effect of acutely injected exogenous estrogen on AKI, male young mice were subjected to $8 \mathrm{~min}$ of $\mathrm{CA}$ and then resuscitated. Fifteen minutes after ROSC, $0.5,5$, or $10 \mu \mathrm{g}$ of $17 \beta$-estradiol or vehicle was injected intravenously. Figure 2 summarizes the findings of the dose-escalation study in young male mice. Estrogen dose-dependently reduces renal injury. Ten micrograms of $17 \beta$-estradiol reduced $\mathrm{sCr}, \mathrm{sUN}$, and VNT by $30 \%$, $41 \%$, and $31 \%$, respectively. Therefore, this dose was selected for the continuation of the study.

\section{Renal blood flow is not altered by estrogen} administration following CA/CPR

To evaluate potential acute systemic effects of estrogen, we measured RRCBF during and after CA/CPR and collected blood samples for arterial blood gas analysis in 


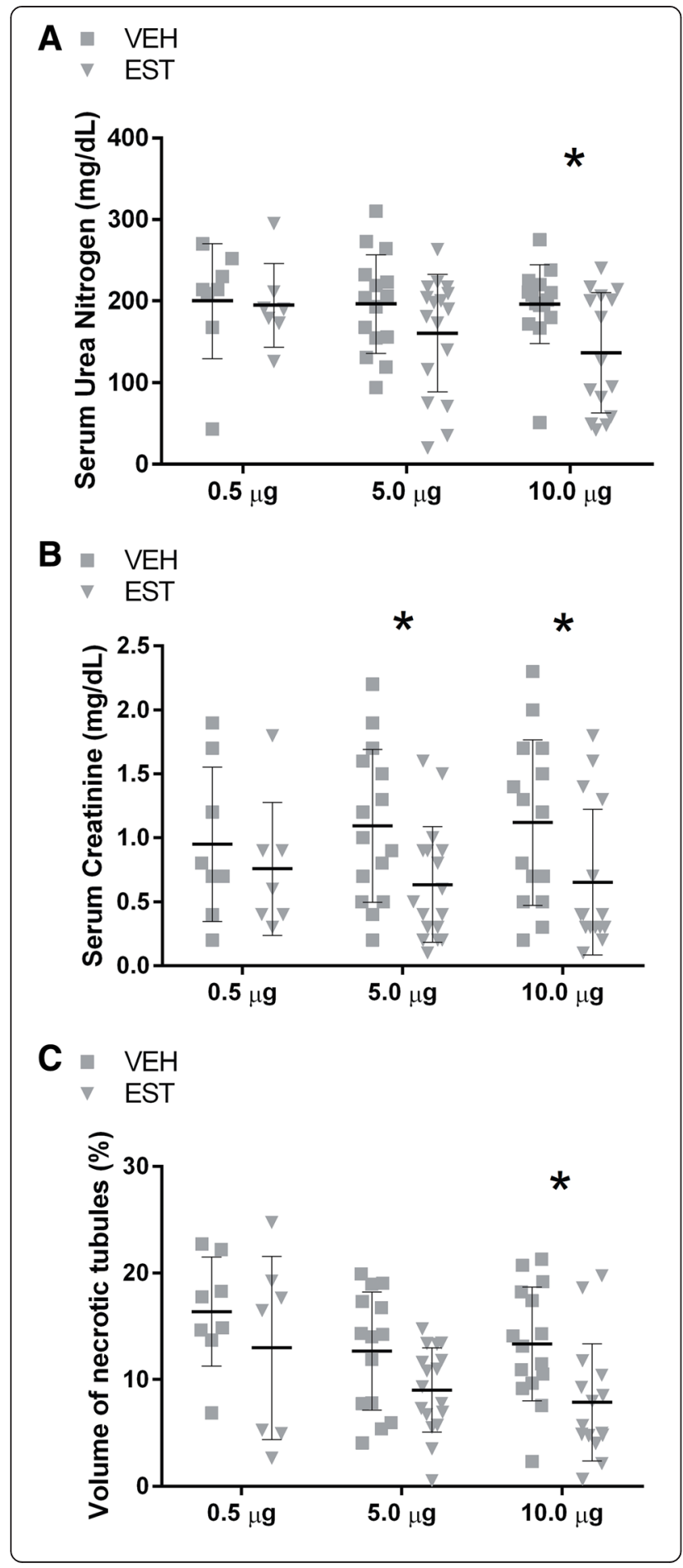

Fig. 2 17 $\beta$-estradiol exerted a dose-dependent renoprotective effect after cardiac arrest and cardiopulmonary resuscitation (CA/CPR) in young males. Blood and tissue samples were collected $24 \mathrm{~h}$ after CA/CPR in young male intravenously injected with $0.5,5$, or $10 \mu \mathrm{g}$ of $17 \beta$-estradiol or vehicle $15 \mathrm{~min}$ after return of spontaneous circulation. Post-arrest administration of $17 \beta$-estradiol exerted a dose-dependent renoprotective effect. At $0.5 \mu \mathrm{g}$, 17ß-estradiol administration exerted no apparent effect on renal injury $24 \mathrm{~h}$ after CA/CPR. Five micrograms caused significant reduction in serum creatinine (b) but not serum urea nitrogen (a) and necrotic tubules (c). At a dose of $10 \mu \mathrm{g}, 17 \beta$-estradiol significantly reduced serum urea nitrogen (a), serum creatinine (b), and necrotic tubules (c) by $41 \%$, $30 \%$, and $31 \%$, respectively. Data are presented as mean \pm standard deviation, $n=8-15,{ }^{*} P<0.05$ by two-way analysis of variance with post hoc Sidak's test. EST 17ß-estradiol-treated mice, VEH vehicle-treated mice

separate cohorts. Figure 3 and Table 1 summarize the results of experiments to measure RRCBF and metabolic parameters in the immediate period following CA/CPR and estrogen administration. There were no significant differences in RRCBF or metabolic parameters between groups.

Sex difference in the severity of AKI after CA/CPR and the effect of post-arrest administration of $17 \beta$-estradiol

To investigate whether there are sex differences in the effect of acutely administered estrogen on AKI after CA/ $\mathrm{CPR}$, young male and female mice were subjected to $\mathrm{CA} / \mathrm{CPR}$ and administered $10 \mu \mathrm{g}$ of either $17 \beta$-estradiol or vehicle $15 \mathrm{~min}$ after ROSC. Table 2 summarizes the baseline and resuscitation data for this protocol. Females required slightly greater resuscitation time and epinephrine than males, but the mortality was not different (time to resuscitate: $123 \pm 33$ versus $155 \pm 30 \mathrm{sec}, P<0.05$; epinephrine dose: $0.52 \pm 0.1$ versus $0.73 \pm 0.1 \mu \mathrm{g} / \mathrm{g}$ body weight, $P<0.05$; mortality: $32 \%$ versus $26 \%, P=0.58$, $\mathrm{n}=30$ and 28 , males versus females). Figure 4 illustrates the effect of estrogen on AKI in both sexes, and Fig. 5 presents representative histologic images. Males suffered greater injury than females, and sex represented $23 \%$ of the total variation in sUN, $25 \%$ in $\mathrm{sCr}$, and $35 \%$ in VNT. Estrogen reduced injury, representing $13 \%$ of the total variation in sUN, $7.2 \%$ in $\mathrm{sCr}$, and $6.4 \%$ in VNT. Post hoc comparison demonstrates that estrogen is renoprotective in males only. Thus, in young male mice, acutely injected estrogen after ischemic insult ameliorates AKI. Young female did not suffer renal injury after $8 \mathrm{~min}$ of $\mathrm{CA}$ and were not affected by the post-arrest administration of estrogen.

\section{Estrogen is acutely renoprotective in old mice of both sexes}

To address the effect of aging on the renoprotective effect of estrogen according to sex, we tested $17 \beta$-estradiol administration in aged mice in both sexes. Eight-minute 


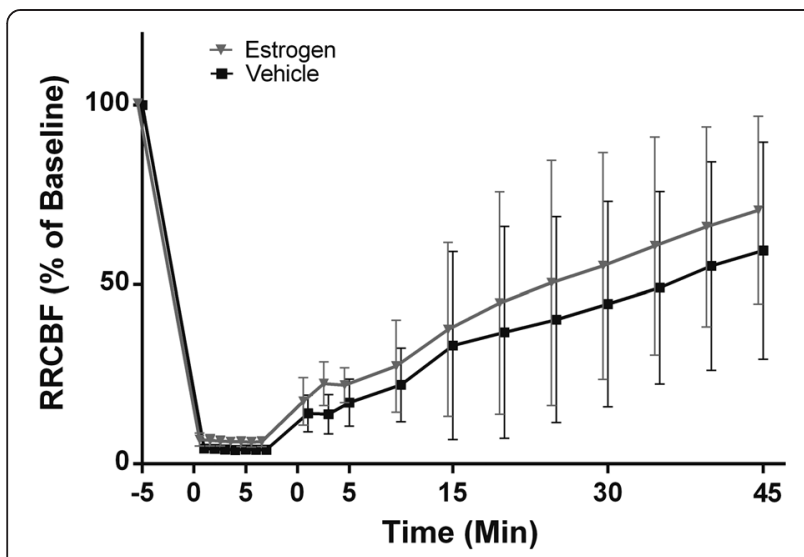

Fig. 3 Regional renal cortical blood flow (RRCBF) is not altered by estrogen administration. Laser Doppler flow of RRCBF was measured in the peri-arrest period for each animal treated with 17/-estradiol or vehicle at 15 min after return of spontaneous circulation (ROSC). The average of the measurement taken 5 min before and immediately before cardiac arrest (CA) served as baseline flow, and all measurements were described as percentage of baseline flow to minimize variation between animals. RRCBF values are not affected by administration of 17ß-estradiol. RRCBF dropped immediately to nonperfusing values on CA. RRCBF remained low after ROSC for 15 min and then gradually returned to the baseline in the 45 -min follow-up period. There was no significant difference in RRCBF between estrogen-treated and vehicle-treated animals at any point. Data are presented as mean \pm standard deviation, $n=6$ or 7 per group

CA/CPR was $100 \%$ lethal in mice of extreme age $(n=7)$. Therefore, we reduced the CA time from 8 to $7 \mathrm{~min}$. Seven-minute CA/CPR in aged mice was associated with similar resuscitation and mortality to $8 \mathrm{~min} \mathrm{CA} / \mathrm{CPR}$ in young mice (age: $83 \pm 2.6$ versus $12 \pm 1.5$ weeks; time to resuscitate: $136 \pm 32$ versus $138 \pm 35 \mathrm{sec}, P=0.78$; mortality: $21 \%$ versus $29 \%, P=0.32, \mathrm{n}=47$ and 82 , aged versus young). There was no sex difference in these parameters (time to resuscitate: $137 \pm 31$ versus $135 \pm 34$ sec, $P=$ 0.86 ; mortality: $30 \%$ versus $10 \%, P=0.07, \mathrm{n}=26$ and 21 , males versus females). These resuscitation data are detailed in Table 2. Figure 6 illustrates the effect of estrogen on AKI in both sexes in aged mice. Overall, in aged mice, estrogen significantly reduced $\mathrm{sUN}, \mathrm{sCr}$, and VNT (representing $23 \%, 16 \%$, and $40 \%$ of total variation, respectively). Post hoc comparison showed significant reduction of $\mathrm{sCr}(80 \%)$ and VNT $(73 \%)$ in aged males. In this protocol, females treated with $17 \beta$-estradiol demonstrated reduced VNT relative to vehicle (a $51 \%$ reduction, $P<0.05$ ), and a protective trend was evident in sUN (45\%, $P=0.08$ ). Therefore, in mice of advanced age, there was no significant effect of sex on renal injury.

Serum estrogen levels in aged female mice are the same as physiologic levels in male mice $24 \mathrm{~h}$ after CA/CPR

We measured serum estradiol levels in estrogen- and vehicle-treated animals $24 \mathrm{~h}$ after CA/CPR to determine whether prolonged differences in estradiol serum levels could contribute to renal outcome. In young female mice, serum levels of estradiol varied considerably in a manner consistent with reproductive cycling $(62 \pm 123 \mathrm{pg} / \mathrm{ml}$, $\mathrm{n}=23$ ). Serum estradiol concentration was negligible in aged females $(16 \pm 9 \mathrm{pg} / \mathrm{ml}, \mathrm{n}=17, P<0.05$ versus young females) and the same as that in young and old males (17 \pm 10 and $11 \pm 8 \mathrm{pg} / \mathrm{ml}, \mathrm{n}=30$ and 17). Serum estradiol was not different $24 \mathrm{~h}$ after treatment whether the animals were treated with $17 \beta$-estradiol or vehicle, suggesting that it returned to physiologic levels prior to $24 \mathrm{~h}$ after administration.

\section{Estrogen receptor expression is upregulated in aged} females compared with young females $24 \mathrm{~h}$ after CA/CPR To elucidate the mechanism of the observed difference in effect of post-arrest estrogen between young and old females and between males and females, we measured levels of the two ERs expressed in renal tissue [27, 28] (ER $\alpha$ and GPER) after CA/CPR. In aged females, the expression of ER $\alpha$ was increased compared with young females $(P=0.01$, Fig. $7 \mathrm{~b}, \mathrm{f})$. By contrast, aged males demonstrated a significant increase in the expression of GPER compared with young males $(P<0.01$, Fig. 7 c, e).

\section{Discussion}

There are three major findings of the present study. First, the advantage of female sex against AKI after whole-body ischemia, which is consistently observed both in our previous study and in the present study, weakens with age. Second, estrogen exerts renoprotective effects even when administered after resuscitation from CA. To the best of our knowledge, this is the first study to demonstrate that exogenous estrogen acts as a potent renoprotective agent when administered in a clinically relevant manner, after whole-body ischemiareperfusion. Third, estrogen injection improves renal outcome in males, but reproductively intact young female are not affected because injury is small, whereas in

Table 1 Post-CA/CPR arterial metabolic values

\begin{tabular}{lllllllllll}
\hline Treatment & $\mathrm{pH}$ & $\mathrm{PCO}_{2}$ & $\mathrm{pO}_{2}$ & $\mathrm{HCO}_{3}^{-}$ & $\mathrm{Hb}$ & $\mathrm{K}^{+}$ & $\mathrm{Na}^{+}$ & $\mathrm{LaC}$ & $\mathrm{Ca}^{++}$ & $\mathrm{BE}$ \\
\hline Estrogen & $6.9(0.1)$ & $47.0(16.9)$ & $226(127)$ & $9.8(3.2)$ & $13.6(0.5)$ & $5.1(0.6)$ & $145(2.6)$ & $8.7(2.9)$ & $1.1(0.1)$ & $-19.8(4.3)$ \\
Vehicle & $6.8(0.2)$ & $54.1(19.4)$ & $141(104)$ & $8.6(3.7)$ & $14.4(1.0)$ & $5.8(0.7)$ & $147(3.8)$ & $10.3(4.5)$ & $1.1(0.1)$ & $-22.4(5.3)$ \\
\hline
\end{tabular}

Data are presented as mean (standard deviation)

CA/CPR cardiac arrest and cardiopulmonary resuscitation 
Table 2 Baseline and resuscitation data according to age, sex, and treatment

\begin{tabular}{|c|c|c|c|c|c|c|c|c|}
\hline Group & Treatment & Number $^{a}$ & Age, week & Body weight, $g$ & $\begin{array}{l}\text { Epinephrine dose, } \\
\mu \mathrm{g} / \mathrm{g} \text { body weight }\end{array}$ & Epinephrine dose, g & CPR time, $\mathrm{s}$ & Survival rate, $\%$ \\
\hline \multirow[t]{3}{*}{ Young male } & VEH & 15 & $11.1(0.4)$ & $25.0(1.6)$ & $0.53(0.09)$ & $13.2(2.0)$ & $129(29)$ & 68 \\
\hline & EST & 15 & $11.2(0.4)$ & $25.1(1.8)$ & $0.51(0.11)$ & $12.7(2.2)$ & $118(37)$ & 68 \\
\hline & $P^{*}$ & & 0.90 & 0.97 & 0.09 & 0.71 & 0.42 & 1 \\
\hline \multirow[t]{3}{*}{ Young female } & VEH & 14 & $12.5(2.0)$ & $19.7(0.8)$ & $0.75(0.08)$ & $14.8(1.6)$ & $158(28)$ & 64 \\
\hline & EST & 14 & $12.9(1.7)$ & $19.9(1.1)$ & $0.71(0.11)$ & $14.0(1.9)$ & $151(33)$ & 88 \\
\hline & $P^{*}$ & & 0.58 & 0.94 & 0.99 & 0.42 & 0.75 & 0.10 \\
\hline \multirow[t]{3}{*}{ Aged male } & VEH & 8 & $83.8(2.9)$ & $34.9(6.8)$ & $0.42(0.10)$ & $14.3(1.9)$ & $136(36)$ & 71 \\
\hline & EST & 10 & $82.6(3.1)$ & $39.2(8.6)$ & $0.36(0.09)$ & $13.6(1.5)$ & $138(27)$ & 67 \\
\hline & $P^{*}$ & & 0.26 & 0.26 & 0.11 & 0.33 & 0.87 & 0.60 \\
\hline \multirow[t]{3}{*}{ Aged female } & VEH & 9 & $81.4(2.4)$ & $29.1(5.1)$ & $0.51(0.13)$ & $14.2(1.9)$ & $142(35)$ & 100 \\
\hline & EST & 10 & $82.2(1.4)$ & $31.1(4.3)$ & $0.42(0.09)$ & $12.9(2.1)$ & $130(35)$ & 83 \\
\hline & $P^{*}$ & & 0.38 & 0.33 & 0.11 & 0.16 & 0.44 & 0.49 \\
\hline
\end{tabular}

Data are presented as mean (standard deviation)

CPR Cardiopulmonary resuscitation, VEH vehicle, EST $17 \beta$-estradiol

a number of survives

*P values shown for Sidak's multiple comparison test or chi-squared test when appropriate

aged mice, estrogen is beneficial to both sexes. Taken together, these three findings indicate that post-arrest estrogen administration is renoprotective in a sex- and age-dependent manner.

We confirmed that females enjoy relative renoprotection after CA as previously reported $[12,13,21]$ and extend this finding with the finding that this advantage weakens in middle age as tubular necrosis becomes equivalent to that of males. Functional measures of injury are still reduced in middle-aged females. Previous studies have demonstrated that female mice enter reproductive senescence by 44-64 weeks [29]. We chose to assess sex difference in middle age precisely because some females, but not all, may have ceased reproductive cycling, thus the mixed finding was expected. To further evaluate the effect of age and reproductive cycling, we used mice of extreme age (78-87 weeks). These aged females lose their advantage both in renal function and in tubular cell death. Serum estradiol levels in aged females decreased to the same level as physiologic level of male mice. Taken together, these data suggest that females lose renoprotection according to age because of changing exposure to estrogen. This would recapitulate our previous findings using ovariectomized young mice [12, 13]. However, whether intact females lose their advantage according to reproductive senescence remains a vital translational question, and we directed this study at this query. Our findings are in line with previous literature studying age-dependent progression of renal damage in female mice. Urbieta-Caceres et al. suggested that aging-induced renal interstitial fibrosis in female mice was mediated by loss of endogenous estrogen [30]. Zheng et al. reported that female mice developed progressive glomerulosclerosis after menopause [31]. Although we did not find any difference between young and aged female surgically naïve animals, those structural abnormalities caused by aging may increase susceptibility to acute ischemic insult in aged females.

The present study demonstrates for the first time a beneficial effect of estrogen on AKI after CA/CPR in male mice. To assess critical translational benefit of estrogen in male mice, we chose the timing of injection at 15 min after ROSC and evaluated three doses. We chose $\mathrm{CA} / \mathrm{CPR}$ as our model for ischemia-reperfusion injury because it replicates key features of clinical ischemiareperfusion, making it clinically relevant. First, it replicates the most common cause of clinical AKI, whole-body hypoperfusion [4]. Second, as can be seen from our data, CA/CPR produces mild-moderate renal injury similar to that seen in clinical ischemia-reperfusion injury. Third, other groups have found that CA/CPR may more closely model ischemic inflammatory, immune, and renal arterial flow changes than occlusion of the renal pedicle, a widely used model of renal ischemia [32,33]. Our data indicate a dose-dependent reduction of renal injury by post-ischemic administration of estrogen. In previous experiments using young female mice exposed to $C A / C P R$, we found that ovariectomy significantly increased injury and that estradiol treatment 7 days prior to ischemic insult, designed to replicate physiologic levels, restored protection [12, 33]. Müller et al. found that increased mortality after focal renal ischemia in male rats compared to female was reversed with estrogen treatment 7 days prior to the insult [10]. Park et al. also reported that estrogen treatment 15 days before renal artery occlusion reduces the postischemic increase of $\mathrm{sUN}$ and $\mathrm{sCr}$ in male mice [11]. 


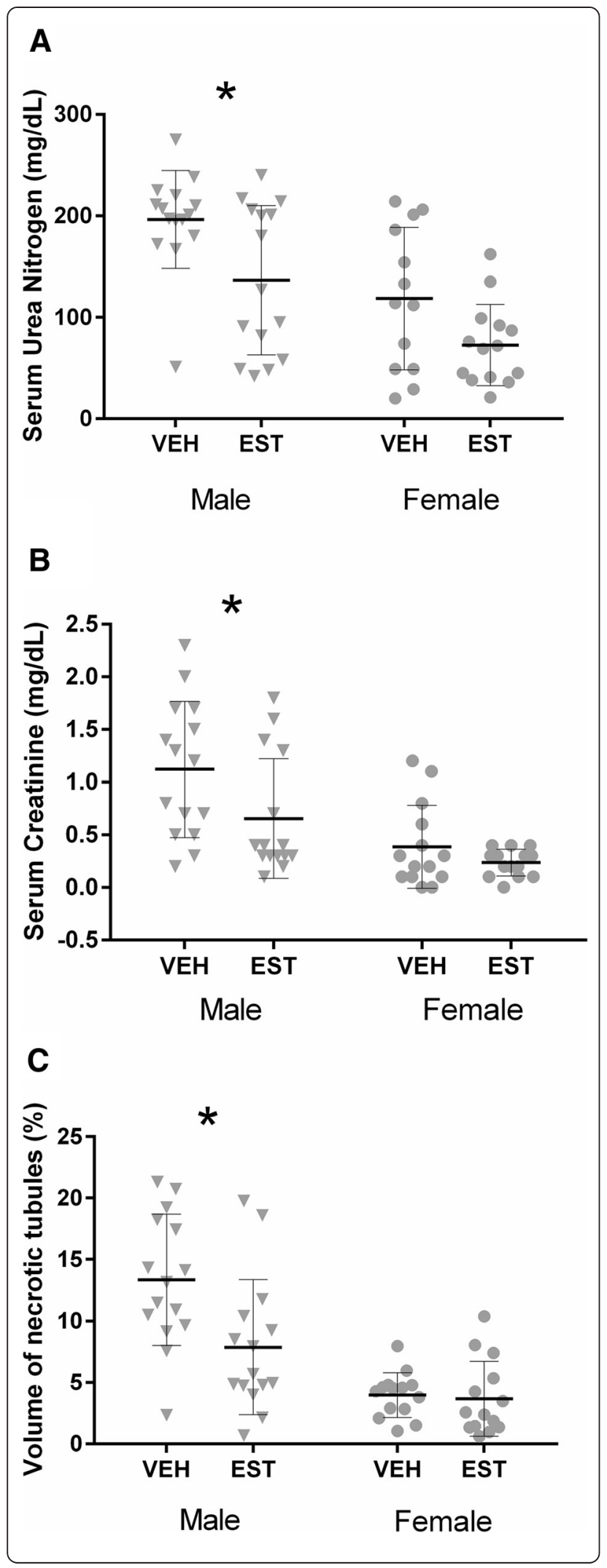

Fig. 4 Sex difference in the severity of acute kidney injury after cardiac arrest and cardiopulmonary resuscitation (CA/CPR) and the effect of post-arrest administration of $17 \beta$-estradiol. Blood and tissue samples were collected $24 \mathrm{~h}$ after CA/CPR in young (10-15 weeks) male or female mice intravenously injected with $10 \mu \mathrm{g}$ of $17 \beta$ estradiol or vehicle $15 \mathrm{~min}$ after return of spontaneous circulation. There was a sex difference in estrogen-mediated amelioration of renal injury following CA/CPR in young mice. Estradiol treatment significantly reduced serum urea nitrogen $(\mathbf{a})$, serum creatinine $(\mathbf{b})$, and tubular cell death (c) in males (triangle), but young females were not affected, because injury was small (circle). Data are presented as mean \pm standard deviation, $\mathrm{n}=14$ or 15 per group, ${ }^{*} P<0.05$ by two-way analysis of variance with post hoc Sidak's test. EST $17 \beta$-estradiol-treated mice, VEH vehicle-treated mice

Takaoka et al. [34] and Tanaka et al. [35] demonstrated with the renal pedicle occlusion model that male rats injected with estrogen 15 min prior to reperfusion demonstrated improved post-ischemic renal outcomes. On the other hand, a recent study which employed intramuscular injection of estrogen 3 days prior to renal ischemiareperfusion surgery found that estrogen's protective effect was limited to ovariectomized female rats and did not protect male rats [36]. The discrepancy of these findings is probably due to the heterogeneity of the experimental model and the length of time of administration. Estrogen dose varied according to the study $(25 \mu \mathrm{g} / \mathrm{kg} \times 7$ days [10], $40-500 \mu \mathrm{g} / \mathrm{kg} \times 14$ days [11], $100 \mu \mathrm{g} / \mathrm{kg} \times$ single dose [35] and $500 \mu \mathrm{g} \times 3$ days [36]); however, no prior study has evaluated the effect of estrogen administration after reperfusion, either whole-body ischemia/reperfusion or renal vascular occlusion. In the present study, only higher dose of estrogen $(400 \mu \mathrm{g} / \mathrm{kg})$ injected during the early reperfusion phase improved the renal outcome in male mice. Estrogens may exert a different mechanism of action depending on the timing of injection, dose, and extent of overall injury. Thus, it is notable that not all studies of estrogen in CA have demonstrated a protective effect. A recent study using a male rat model of ventricular fibrillation and resuscitation reported that estrogen administration did not result in beneficial myocardial effect or impact survival. The survival rates $3 \mathrm{~h}$ after resuscitation in this severe-injury model are $0 \%$ versus $33 \%, P=0.32$, estrogen versus saline, for bolus injection and $63 \%$ versus $100 \%, P<0.05$, estrogen versus saline, for continuous injection [37]. The present study uses a CA/CPR model which demonstrates a mild injury and survival of more than $65 \%$ in order to assess renal outcome $24 \mathrm{~h}$ after ROSC, and this may explain the apparently discordant result.

Pre-ischemic estrogen alters outcome of focal renal ischemia via nitric oxide and endothelin-1 [10, 34]. Because both of these mediators are believed to act on renal blood flow, our findings that neither RRCBF nor systemic metabolic parameters are affected by estrogen 


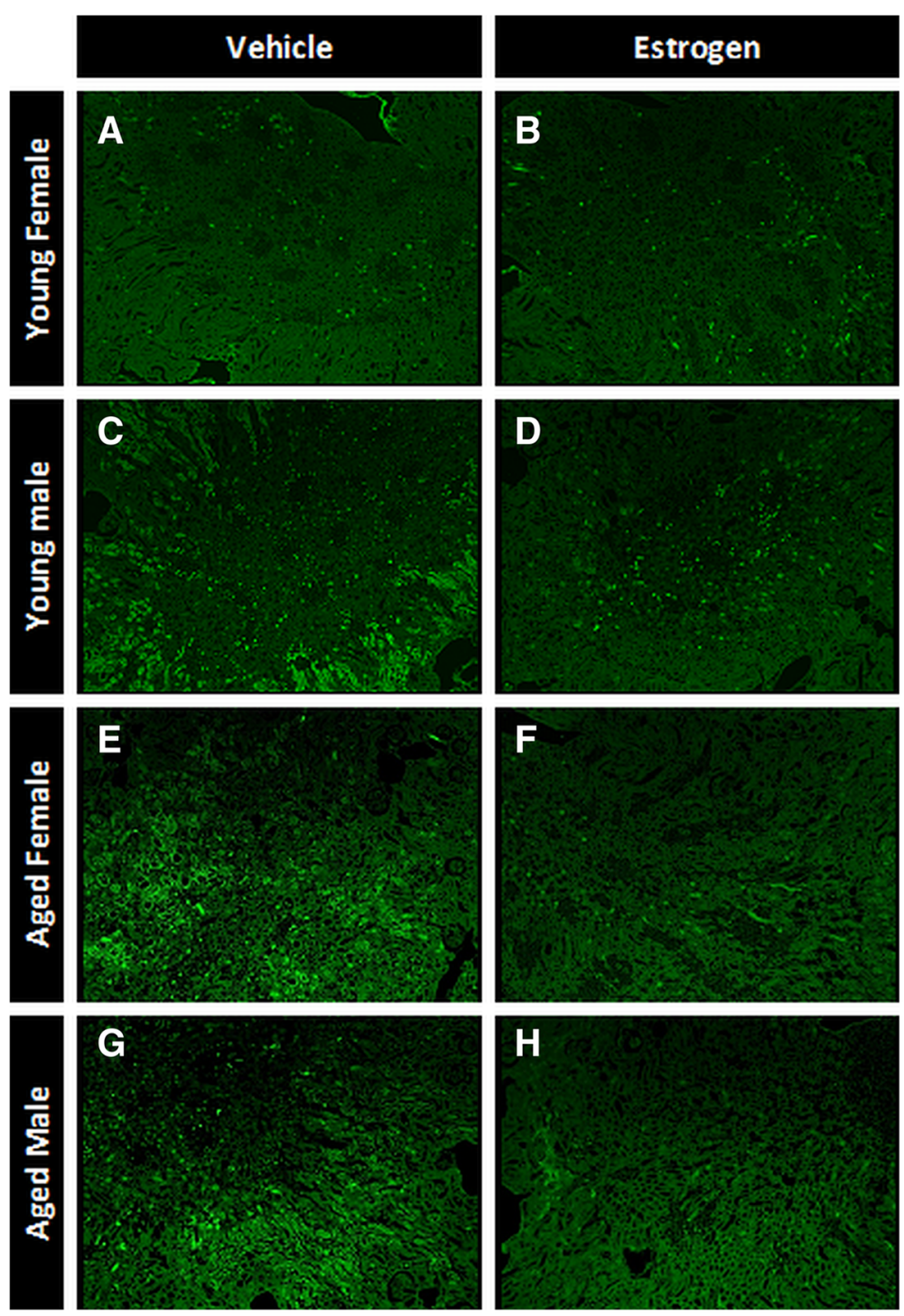

Fig. 5 Representative photomicrographs of Flouro-Jade B-stained kidney section $24 \mathrm{~h}$ after cardiac arrest and cardiopulmonary resuscitation. Mouse kidneys were perfusion-fixed and removed $24 \mathrm{~h}$ after cardiac arrest and cardiopulmonary resuscitation and then stained with Flouro-Jade B, which stains early necrotic cells bright green. a Young female vehicle. $\mathbf{b}$ Young female estrogen. $\mathbf{c}$ Young male vehicle. $\mathbf{d}$ Young male estrogen. e Aged female vehicle. $\mathbf{f}$ Aged female estrogen. $\mathbf{g}$ Aged male vehicle. $\mathbf{h}$ Aged male estrogen

during the post-arrest period suggest that the mechanism of acute renoprotection by post-arrest estrogen may be distinct from that of chronic or pre-ischemic administration. Since no prior study addresses post-treatment with estrogen in the kidney, we note that after experimental stroke estrogen exerted a protective effect due to enhanced cerebral blood flow [38, 39]. In our wholebody ischemia model, we found that estrogen does not alter RRCBF or systemic metabolic parameters in the recovery period up to $45 \mathrm{~min}$ following $\mathrm{CA} / \mathrm{CPR}$. We cannot eliminate the possibility that renal medullary but not renal cortical blood flow is affected by estrogen, as it is reported that even though cortical blood flow fully recovers in 30-45 min after bilateral occlusion of the renal arteries and veins and reperfusion, medullary blood flow remains compromised for prolonged periods that are associated with a long-term decline in renal function $[40,41]$. However, this investigation is focused on acute, 24-h outcomes, and estrogen mediation of long-term outcome was not assessed in this study. Another possibility is that the use of isoflurane in our study confounds the evaluation of blood flow, as it is a vasodilator. An additional possible limitation regarding the use of isoflurane is its well-characterized renoprotective effect [42]. It is not possible to perform our study without anesthesia; we carefully designed experiments to exclude differential effect of either vasodilatory or renoprotective properties of isoflurane. As all animals received the same 


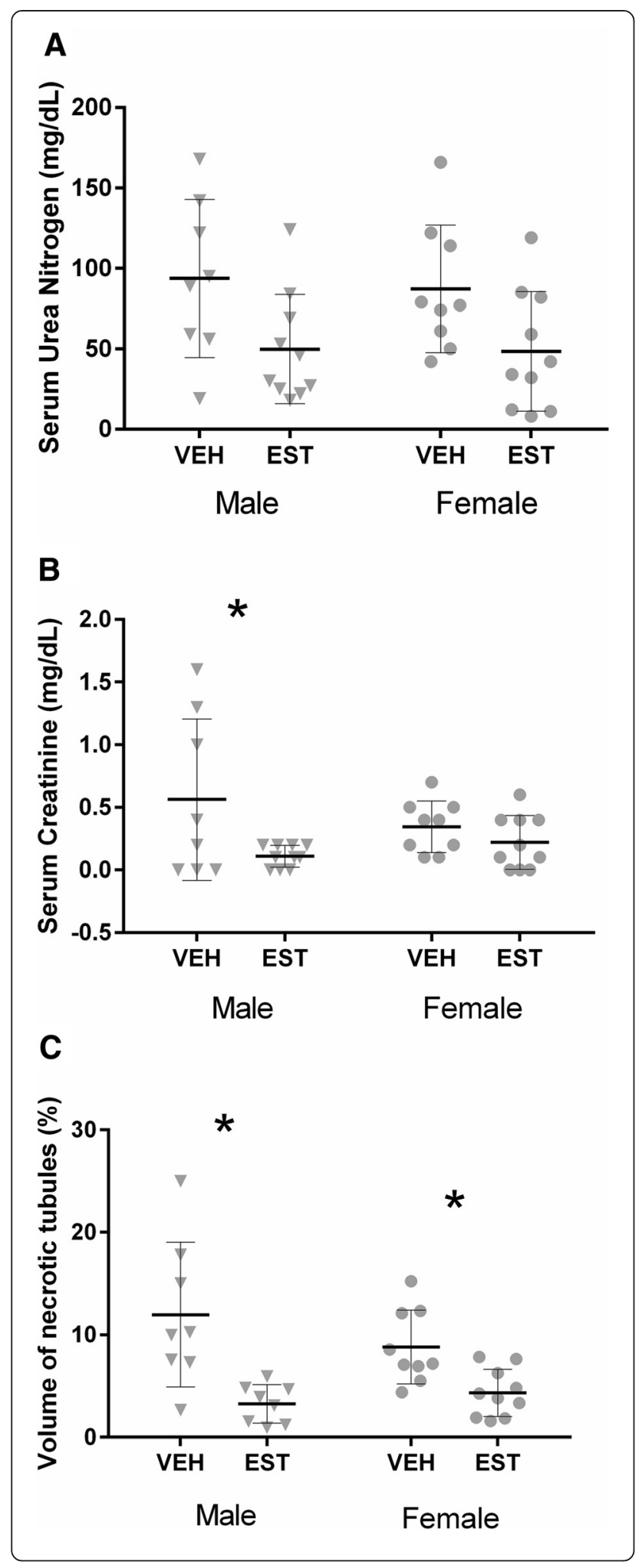

Fig. 6 17ß-estradiol after cardiac arrest and cardiopulmonary resuscitation (CA/CPR) ameliorates renal injury in old mice of both sexes. Blood and tissue samples were collected $24 \mathrm{~h}$ after CAVCPR in aged (78-87 weeks) male or female mice intravenously injected with $10 \mu \mathrm{g}$ of $17 \beta$-estradiol or vehicle $15 \mathrm{~min}$ after return of spontaneous circulation. Unlike in young mice, in this group of mice at advanced age, there was no significant effect of sex on renal injury. Estradiol treatment significantly reduced serum creatinine (b) and tubular cell death (c) in aged males (triangle) and tubular cell death (c) in aged females (circle). Serum urea nitrogen was not affected by estrogen treatment in either aged males or aged females (a). Data are presented as mean \pm standard deviation, $n=8-10$ per group, ${ }^{*} P<0.05$ by two-way analysis of variance with post hoc Sidak's test. EST $17 \beta$-estradiol-treated mice, VEH vehicle-treated mice

concentration of isoflurane, no observed effect can be due to the influence of isoflurane alone.

In the present study, efficacy of post-ischemic estrogen injection was observed amongst young mice only in males. On the other hand, estrogen was renoprotective in old mice of both sexes. In our previous studies, we found that deletion of ERs $\alpha, \beta$, and GPER did not interfere with protection against renal injury from ischemia/ reperfusion when estrogen was administered for a week prior to CA/CPR $[12,13]$. In evaluating these findings, we hypothesized that pre-ischemic and repeated dosing of estrogen could protect the kidney through multiple mechanisms mediated by more than one receptor; thus, deletion of a single receptor would not abrogate the protective effect. As acute and chronic administrations of estrogen are differentially protective in neurologic ischemia [43], this might also be the case in renal ischemic injury. Thus, it is essential to evaluate involvement of renal ERs in the effect we observed. Since aged females are in a low-estrogen environment compared with young females, we hypothesized that ER expression levels differ between the two, and this might explain the different response to the exogenous estrogen. We therefore measured renal ER $\alpha$ and GPER levels in animals not treated with estrogen. We found that the expression of ER $\alpha$ in aged females was increased compared with young females $24 \mathrm{~h}$ after CA/CPR. This finding in animals after CA/CPR is similar to those of others: in surgically naïve animals, ER $\alpha$ expression increases with age in renal tissue [44]. Our finding is limited in that the 24-h time point may not precisely replicate the levels present at the time of reperfusion; therefore, the inference of mechanistic association should be interpreted with caution. In heart [45] and brain [46, 47], ER activation reduces ischemic injury. In light of these findings and in light of recent data indicating $\mathrm{ER} \alpha$ as a mediator of protective estrogen signaling in female rats with pulmonary hypertension-induced right ventricular failure [48], we speculate (with the above limitations) that protective acute estrogen effects in aged females are mediated at 

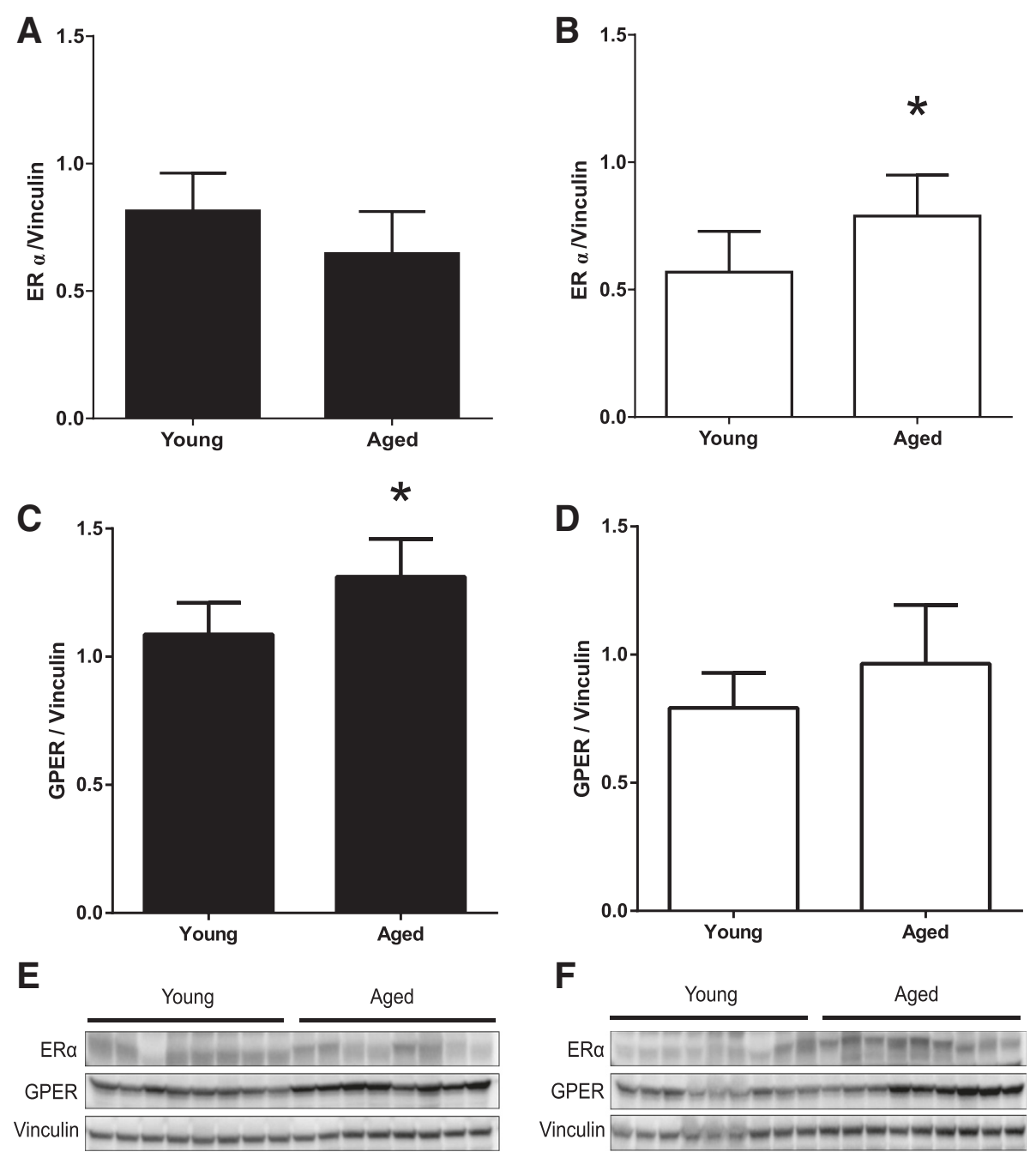

\section{Male}

Female

Fig. 7 Renal expression of ERa and GPER $24 \mathrm{~h}$ after cardiac arrest and cardiopulmonary resuscitation (CA/CPR). Aging is associated with increased renal expression of ERa in female mice and GPER in male mice $24 \mathrm{~h}$ after CA/CPR. ERa and GPER expressions were determined in kidney homogenates of young (10-15 weeks) or aged (78-87 weeks) male ( $\mathbf{a}, \mathbf{c}, \mathbf{e})$ or female $(\mathbf{b}, \mathbf{d}, \mathbf{f})$ mice harvested after $24 \mathrm{~h}$ of CA/CPR by Western blotting with subsequent quantification by densitometry. Densitometric analyses for ERa and GPER are shown in (a-d). Western blots including homogenates from all animals ( $\mathrm{n}=8$ or 9 per group) are shown in $(\mathbf{e}, \mathbf{f})$. Note the increase in ERa abundance in aged females $(\mathbf{b}, \mathbf{f})$ and increase in GPER abundance in aged males $(\mathbf{c}, \mathbf{e})$. Data are presented as mean \pm standard deviation, $\mathrm{n}=8$ or 9 per group, ${ }^{*} P<0.05$ by unpaired $t$ test. ER estrogen receptor, GPER G protein-coupled estrogen receptor

least in part by ER $\alpha$, and further investigation will test this hypothesis.

Sex differences in the expression of ER during aging [44] and in neuroprotective effects of ER agonists have been reported [49]. Broughton et al. found that GPER expression was increased in the brain of male mice but not of female mice after transient focal cerebral ischemia [50] and that GPER activation worsens outcome in males but that an opposite protective effect occurs in females [49]. Interestingly, the expression of GPER in kidney $24 \mathrm{~h}$ after CA/CPR was increased in aged male compared with young male mice in our study. The underlying mechanisms responsible for the estrogen's protective effect to renal ischemic injury observed in our study require further investigation, particularly with regard to sex difference. Androgens, including testosterone, are reported to increase the susceptibility of males to ischemic renal injury [10, 11]. Myocardial ischemia reperfusion injury in male rats aggravated cardiac damage through androgen receptor [51]. The interaction of sex hormones besides estrogen and their change in the aging process might modify the effect of estrogen's renoprotection in males. Together, these findings highlight the complex nature of endogenous estrogen signaling, which may 
vary between different physiological and disease settings. Sex should be considered in identification of the underlying mechanism responsible for the effect of estrogen.

In addition to the sex and age specificity of estrogen's renoprotective mechanisms, it is possible that estrogen exerts its effect differently because of timing. We acknowledge that most previous studies are designed in the aspect of hormone replacement therapy, mostly involving long-term drug pretreatment before experimental ischemia, and that more work is required to fully evaluate the efficacy of estrogen as a potent therapeutic agent. Our study, designed to evaluate efficacy of acute and transient estrogen exposure, shows that the renoprotective effect is rapid, exerted within $24 \mathrm{~h}$ of ischemia reperfusion, perhaps sooner, suggesting one of the nonnuclear, rapid actions of estrogen $[45,52]$. The fact that serum estradiol levels have returned to physiologic levels within $24 \mathrm{~h}$ after estradiol injection reinforces the argument of estrogen's rapid action. In our recent in vitro study, we found that hyperpermeability of glomerular endothelial cells after ischemia was prevented by estrogen in part through GPER [21]. Interestingly, in that study, the significant decrease in glomerular permeability by estrogen observed after $4 \mathrm{~h}$ of re-oxygenation was no longer evident at $8 \mathrm{~h}$, suggesting that estrogen's effect is acute and transient. Preserved glomerular barrier integrity during the acute phase of reperfusion might prevent subsequent tubular dysfunction and tubular cell death. We did not assess whether post-arrest estrogen injection alters glomerular permeability or GPER expression at an early phase of reperfusion in the present study, which was focused on whether estrogen exerted any acute beneficial effect in renal ischemia. Further investigation of glomerular permeability effects of estrogen in vivo might delineate a mechanism of the protective effect we observed. We did not find any difference in 24-h survival rate between estrogen-treated animals and vehicle-treated animals in our potassium-induced CA model (76 \% versus $66 \%, P=0.30$, estrogen versus vehicle), and estrogentreated animals had less kidney injury.

\section{Conclusions}

In summary, we report that estrogen injection shortly after resuscitation from CA ameliorates renal injury in young males. Young females were not protected by estrogen, because of reduced renal injury from $\mathrm{CA} / \mathrm{CPR}$ itself relative to males and aged females. In aged females, the protective effect of exogenous estrogen may be recovered with loss of endogenous estrogen.

The magnitude of the effect in our model offers promise for future translational study. For successful translation, an observed preclinical effect should match with the population at risk for the disease. Our study suggests that acute, estrogen-mediated renoprotection is selective to males and aged females, precisely the population at risk for clinical AKI. Our findings suggest that further investigation of estrogen-mediated renoprotection should focus on rapid effects and whether in aged animals these are mediated thorough cognate ERs.

\section{Key messages}

- Aging reduces the female advantage in renal outcome after whole-body ischemia reperfusion injury.

- When given in a clinically relevant manner after cardiac arrest and cardiopulmonary resuscitation, estrogen reduces renal injury in male and aged female mice.

- This study provides early evidence that efforts to translate this first demonstration of an estrogenic acute post-resuscitation renoprotective effect may best be focused on rapid effects which in the aged may be mediated by cognate estrogen receptors.

\section{Abbreviations}

AKl: Acute kidney injury; BSA: Bovine serum albumin; CA: Cardiac arrest: CPR: Cardiopulmonary resuscitation; EKG: Electrocardiogram; ER: Estrogen receptor; GPER: G protein-coupled estrogen receptor; HRP: Horseradish peroxidase; ROSC: Return of spontaneous circulation; RRCBF: Regional renal cortical blood flow; sCr: Serum creatinine; sUN: Serum urea nitrogen; TBST: Tris-buffered saline with Tween-20; VNT: Volume of necrotic tubules.

\section{Competing interests}

The authors declare that they have no competing interests.

\section{Authors' contributions}

$\mathrm{MI}$ carried out the in vivo studies, analyzed data, and drafted the manuscript. TS performed in vivo studies and drafted the manuscript. AV carried out immunoblotting, analyzed data, and drafted the manuscript. TL conceived immunoblotting experiments, analyzed data, and drafted the manuscript. SA designed the study, drafted the manuscript, and critically revised the manuscript. MPH led the research team, designed the study, analyzed data, and drafted the manuscript. All authors read and approved the final manuscript.

\section{Acknowledgments}

This work was supported by a grant (DK090754) from the National Institute of Diabetes and Digestive and Kidney Diseases (US) to MPH and a grant (101BX002042-01A2) from the VA Merit Review Award (US) to TL.

\section{Author details}

${ }^{1}$ Department of Anesthesiology and Perioperative Medicine, Oregon Health and Science University, 3181 SW Sam Jackson Park Road, Portland, OR 97239, USA. ${ }^{2}$ Division of Pulmonary, Critical Care, Sleep and Occupational Medicine, Indiana University School of Medicine, Joseph E. Walther Hall, R3 C400 980 W. Walnut St., Indianapolis, IN 46202, USA. ${ }^{3}$ Richard L. Roudebush VA Medical Center, 1481 W 10th St, Indianapolis, IN 46202, USA. ${ }^{4}$ Department of Internal Medicine, Division of Nephrology and Hypertension, Oregon Health \& Science University, 3181 SW Sam Jackson Park Road, Portland, OR 97239, USA.

Received: 11 June 2015 Accepted: 26 August 2015

Published online: 18 September 2015

\section{References}

1. Kheterpal S, Tremper KK, Englesbe MJ, O'Reilly M, Shanks AM, Fetterman DM, et al. Predictors of postoperative acute renal failure after noncardiac surgery in patients with previously normal renal function. Anesthesiology. 2007;107:892-902. 
2. Kheterpal S, Tremper KK, Heung M, Rosenberg AL, Englesbe M, Shanks AM, et al. Development and validation of an acute kidney injury risk index for patients undergoing general surgery: results from a national data set. Anesthesiology. 2009;110:505-15.

3. Kidney disease: Improving global outcomes (KDIGO) acute kidney injury work group. KDIGO clinical practice guideline for acute kidney injury. Kidney Int Suppl (2011). 2012;2:6.

4. Hou SH, Bushinsky DA, Wish JB, Cohen JJ, Harrington JT. Hospital-acquired renal insufficiency: a prospective study. Am J Med. 1983;74:243-8.

5. Mehta RL, Pascual MT, Soroko S, Savage BR, Himmelfarb J, Ikizler TA, et al. Spectrum of acute renal failure in the intensive care unit: the PICARD experience. Kidney Int. 2004;66:1613-21.

6. Xue JL, Daniels F, Star RA, Kimmel PL, Eggers PW, Molitoris BA, et al. Incidence and mortality of acute renal failure in Medicare beneficiaries, 1992 to 2001. J Am Soc Nephrol. 2006;17:1135-42.

7. Talabani B, Zouwail S, Pyart RD, Meran S, Riley SG, Phillips AO. Epidemiology and outcome of community-acquired acute kidney injury. Nephrology (Carlton). 2014;19:282-7.

8. Song HK, Grab JD, O'Brien SM, Welke KF, Edwards F, Ungerleider RM. Gender differences in mortality after mitral valve operation: evidence for higher mortality in perimenopausal women. Ann Thorac Surg. 2008:85:2040-4. discussion 2045.

9. Lapi F, Azoulay L, Niazi MT, Yin H, Benayoun S, Suissa S. Androgen deprivation therapy and risk of acute kidney injury in patients with prostate cancer. JAMA. 2013;310:289-96.

10. Müller V, Losonczy G, Heemann U, Vannay A, Fekete A, Reusz G, et al. Sexual dimorphism in renal ischemia-reperfusion injury in rats: possible role of endothelin. Kidney Int. 2002;62:1364-71.

11. Park KM, Kim Jl, Ahn Y, Bonventre AJ, Bonventre JV. Testosterone is responsible for enhanced susceptibility of males to ischemic renal injury. J Biol Chem. 2004;279:52282-92.

12. Hutchens MP, Nakano T, Kosaka Y, Dunlap J, Zhang W, Herson PS, et al. Estrogen is renoprotective via a nonreceptor-dependent mechanism after cardiac arrest in vivo. Anesthesiology. 2010;112:395-405.

13. Hutchens MP, Kosaka Y, Zhang W, Fujiyoshi T, Murphy S, Alkayed N, et al. Estrogen-mediated renoprotection following cardiac arrest and cardiopulmonary resuscitation is robust to GPR30 gene deletion. PLoS One. 2014:9:e99910.

14. Xu SY, Pan SY. The failure of animal models of neuroprotection in acute ischemic stroke to translate to clinical efficacy. Med Sci Monit Basic Res. 2013;19:37-45

15. van der Worp HB, Howells DW, Sena ES, Porritt MJ, Rewell S, O'Collins V, et al. Can animal models of disease reliably inform human studies? PLoS Med. 2010;7:e1000245.

16. Wiebers DO, Adams Jr HP, Whisnant JP. Animal models of stroke: are they relevant to human disease? Stroke. 1990;21:1-3.

17. Laake JH, Bugge JF. Acute renal failure in critically ill patients. Tidsskr Nor Laegeforen. 2010;130:158-61.

18. Wang $X$, Bonventre JV, Parrish AR. The aging kidney: increased susceptibility to nephrotoxicity. Int J Mol Sci. 2014;15:15358-76.

19. Anderson S, Eldadah B, Halter JB, Hazzard WR, Himmelfarb J, Horne FM, et al. Acute kidney injury in older adults. J Am Soc Nephrol. 2011;22:28-38.

20. Hutchens MP, Dunlap J, Hurn PD, Jarnberg PO. Renal ischemia: does sex matter? Anesth Analg. 2008;107:239-49.

21. Hutchens MP, Fujiyoshi T, Komers R, Herson PS, Anderson S. Estrogen protects renal endothelial barrier function from ischemia-reperfusion in vitro and in vivo. Am J Physiol Renal Physiol. 2012;303:F377-85.

22. Hutchens MP, Traystman RJ, Fujiyoshi T, Nakayama S, Herson PS Normothermic cardiac arrest and cardiopulmonary resuscitation: a mouse model of ischemia-reperfusion injury. J Vis Exp. 2011. doi:10.3791/3116.

23. Noppens RR, Kofler J, Hurn PD, Traystman RJ. Dose-dependent neuroprotection by 17beta-estradiol after cardiac arrest and cardiopulmonary resuscitation. Crit Care Med. 2005:33:1595-602.

24. England BG, Niswender GD, Midgley Jr AR. Radioimmunoassay of estradiol17beta without chromatography. J Clin Endocrinol Metab. 1974;38:42-50.

25. Gundersen HJ, Jensen EB, Kieu K, Nielsen J. The efficiency of systematic sampling in stereology-reconsidered. J Microsc. 1999;193:199-211.

26. Lahm T, Albrecht M, Fisher AJ, Selej M, Patel NG, Brown JA, et al. 17beta-Estradiol attenuates hypoxic pulmonary hypertension via estrogen receptor-mediated effects. Am J Respir Crit Care Med. 2012;185:965-80.
27. Taylor AH, Al-Azzawi F. Immunolocalisation of oestrogen receptor beta in human tissues. J Mol Endocrinol. 2000;24:145-55.

28. Lindsey $\mathrm{SH}$, Yamaleyeva LM, Brosnihan KB, Gallagher PE, Chappell MC. Estrogen receptor GPR30 reduces oxidative stress and proteinuria in the salt-sensitive female mRen2.Lewis rat. Hypertension. 2011:58:665-71.

29. Miura K, Goldstein RS, Morgan DG, Pasino DA, Hewitt WR, Hook JB. Age-related differences in susceptibility to renal ischemia in rats. Toxicol Appl Pharmacol. 1987:87:284-96.

30. Urbieta-Caceres VH, Syed FA, Lin J, Zhu XY, Jordan KL, Bell CC, et al. Age-dependent renal cortical microvascular loss in female mice. Am J Physiol Endocrinol Metab. 2012;302:E979-86.

31. Zheng F, Plati AR, Potier M, Schulman Y, Berho M, Banerjee A, et al. Resistance to glomerulosclerosis in B6 mice disappears after menopause. Am J Pathol. 2003;162:1339-48.

32. Li X, Liu M, Bedja D, Thoburn C, Gabrielson K, Racusen L, et al. Acute renal venous obstruction is more detrimental to the kidney than arterial occlusion: implication for murine models of acute kidney injury. Am J Physiol Renal Physiol. 2012;302:F519-25.

33. Burne-Taney MJ, Kofler J, Yokota N, Weisfeldt M, Traystman RJ, Rabb H. Acute renal failure after whole body ischemia is characterized by inflammation and T cell-mediated injury. Am J Physiol Renal Physiol. 2003;285:F87-94

34. Takaoka M, Yuba M, Fujii T, Ohkita M, Matsumura Y. Oestrogen protects against ischaemic acute renal failure in rats by suppressing renal endothelin-1 overproduction. Clin Sci (Lond). 2002;103:434S-7.

35. Tanaka R, Tsutsui H, Kobuchi S, Sugiura T, Yamagata M, Ohkita M, et al. Protective effect of 17beta-estradiol on ischemic acute kidney injury through the renal sympathetic nervous system. Eur J Pharmacol. 2012;683:270-5.

36. Iran-Nejad A, Nematbakhsh M, Eshraghi-Jazi F, Talebi A. Preventive role of estradiol on kidney injury induced by renal ischemia-reperfusion in male and female rats. Int J Prev Med. 2015;6:22.

37. Miao Y, Edelheit A, Velmurugan S, Borovnik-Lesjak V, Radhakrishnan J, Gazmuri RJ. Estrogen fails to facilitate resuscitation from ventricular fibrillation in male rats. Am J Transl Res. 2015;7:522-34.

38. Yang SH, Shi J, Day AL, Simpkins JW. Estradiol exerts neuroprotective effects when administered after ischemic insult. Stroke. 2000;31:745-9. discussion 749-50.

39. McCullough LD, Alkayed NJ, Traystman RJ, Williams MJ, Hurn PD. Postischemic estrogen reduces hypoperfusion and secondary ischemia after experimental stroke. Stroke. 2001;32:796-802.

40. Regner KR, Zuk A, Van Why SK, Shames BD, Ryan RP, Falck JR, et al. Protective effect of 20-HETE analogues in experimental renal ischemia reperfusion injury. Kidney Int. 2009;75:511-7.

41. Regner KR, Roman RJ. Role of medullary blood flow in the pathogenesis of renal ischemia-reperfusion injury. Curr Opin Nephrol Hypertens. 2012;21:33-8.

42. Lee HT, Kim M, Kim M, Kim N, Billings 4th FT, D'Agati VD, et al. Isoflurane protects against renal ischemia and reperfusion injury and modulates leukocyte infiltration in mice. Am J Physiol Renal Physiol. 2007;293:F713-22.

43. Gulinello M, Lebesgue D, Jover-Mengual T, Zukin RS, Etgen AM. Acute and chronic estradiol treatments reduce memory deficits induced by transient global ischemia in female rats. Horm Behav. 2006;49:246-60.

44. Sharma PK, Thakur MK. Estrogen receptor alpha expression in mice kidney shows sex differences during aging. Biogerontology. 2004;5:375-81.

45. Deschamps AM, Murphy E, Sun J. Estrogen receptor activation and cardioprotection in ischemia reperfusion injury. Trends Cardiovasc Med. 2010;20:73-8.

46. Noppens RR, Kofler J, Grafe MR, Hurn PD, Traystman RJ. Estradiol after cardiac arrest and cardiopulmonary resuscitation is neuroprotective and mediated through estrogen receptor-beta. J Cereb Blood Flow Metab. 2009;29:277-86.

47. Tang $H$, Zhang $Q$, Yang L, Dong Y, Khan M, Yang F, et al. GPR30 mediates estrogen rapid signaling and neuroprotection. Mol Cell Endocrinol. 2014;387:52-8

48. Frump AL, Goss KN, Vayl A, Albrecht M, Fisher AJ, Tursunova R, et al. Estradiol improves right ventricular function in rats with severe angioproliferative pulmonary hypertension: effects of endogenous and exogenous sex hormones. Am J Physiol Lung Cell Mol Physiol. 2015;308:L873-90. 
49. Broughton BR, Brait VH, Guida E, Lee S, Arumugam TV, Gardiner-Mann CV, et al. Stroke increases $g$ protein-coupled estrogen receptor expression in the brain of male but not female mice. Neurosignals. 2013;21:229-39.

50. Broughton BR, Brait VH, Kim HA, Lee S, Chu HX, Gardiner-Mann CV, et al. Sex-dependent effects of $\mathrm{G}$ protein-coupled estrogen receptor activity on outcome after ischemic stroke. Stroke. 2014;45:835-41.

51. Le TY, Ashton AW, Mardini M, Stanton PG, Funder JW, Handelsman DJ, et al. Role of androgens in sex differences in cardiac damage during myocardial infarction. Endocrinology. 2014;155:568-75.

52. Hammes SR, Levin ER. Minireview: Recent advances in extranuclear steroid receptor actions. Endocrinology. 2011;152:4489-95.

\section{Submit your next manuscript to BioMed Central} and take full advantage of:

- Convenient online submission

- Thorough peer review

- No space constraints or color figure charges

- Immediate publication on acceptance

- Inclusion in PubMed, CAS, Scopus and Google Scholar

- Research which is freely available for redistribution 